\title{
Awareness in the Context of Prevalence of Vitamin A Deficiency Among Households in Western Kenya Using a Cross-Sectional Study
}

\author{
Mary Anyango Oyunga ${ }^{1}$, David Okeyo Omondi ${ }^{2}$, Fredrick Kobina Ebo Grant ${ }^{3}$ \\ ${ }^{1}$ Kenya Agriculture \& Livestock Research Organization, Kisumu, Kenya \\ ${ }^{2}$ Department of Nutrition and Health, Nutritionists and Dieticians Institute, Maseno University, Kisumu, Kenya \\ ${ }^{3}$ International Potato Center, Dar es Salaam, Tanzania
}

Email address:

oyungam2010@gmal.com (M. A. Oyunga)

\section{To cite this article:}

Mary Anyango Oyunga, David Okeyo Omondi, Fredrick Kobina Ebo Grant. Awareness in the Context of Prevalence of Vitamin A Deficiency Among Households in Western Kenya Using a Cross-Sectional Study. Journal of Food and Nutrition Sciences.

Vol. 4, No. 3, 2016, pp. 55-64. doi: 10.11648/j.jfns.20160403.13

Received: April 20, 2016; Accepted: April 29, 2016; Published: May 13, 2016

\begin{abstract}
Increasing awareness of the role of vitamin A (VA) in human health has led to international efforts to eliminate VA deficiency (VAD) as a public health problem. This paper examined community awareness of existence, signs and symptoms, causes, control of VAD as well as attitudes, so as to identify knowledge gaps among health workers and caretakers/mothers. This was a community-based study within the catchment areas served by health facilities offering antenatal care services in Busia and Bungoma counties in Western Kenya. The study adopted cross-sectional design and purposive sampling technique. Eight focus group discussions (FGDs) were conducted with pregnant and lactating mothers and eight key informant interviews with those in charge of health facilities until saturation. Data was audio recorded, transcribed, coded and thematically analyzed using ATLAS.ti version 6 software. Most respondents stated having heard about VA/VAD but very few had the correct knowledge of signs and symptoms, causes, and control of VAD. Their attitudes towards VAD and its control were generally indifferent with a general belief that they had no control over their circumstances to reduce VAD. Although VAD was prevalent in the study area, majority of the people in the community had low awareness. This study, therefore, stresses the need for health education to raise community's awareness on VAD in such settings in order to augment prevention, control and elimination efforts.
\end{abstract}

Keywords: Vitamin A Deficiency, Awareness, Community, Western Kenya

\section{Introduction}

Vitamin A (VA) deficiency (VAD) remains a widespread public health problem among women and children in the developing world. It is a major contributor to child morbidity in sub-Saharan Africa, where an estimated 42\% (43.2 million) of children under five-years have $\operatorname{VAD}[1,2]$, defined as serum retinol concentration less than $0.70 \mu \mathrm{mol} / \mathrm{L}$, and which reflects a severe public health problem [3]. According to 1999 Kenya Micronutrient Survey [4], 76\% of children had VAD making Kenya one of the countries with low serum levels according to the World Health Organization (WHO), this has been confirmed by surveys in children $[5,6$,
7, 8], and in women [9, 10], and by 2008, the VAD prevalence had risen to $84 \%$ [11]. Kenya loses 121,000 DALYs annually that is attributable to VAD. This amounts to, between 0.5 and 1 percent of the gross national product, yearly [12]. Commonly, VAD occurs as a result of an environment of ecological, social and economical deprivation, whereby a habitually deficient dietary intake of VA exists together with severe infections [13, 14]. The consequences of VAD include limited growth, weakened immunity, Xerophthalmia leading to blindness, and increase in mortality [15].

Currently, the government of Kenya is providing vitamin A supplementation (VAS) to children under 5 usually at antenatal visits and during vaccination exercises, however, 
Western province of Kenya still has the lowest VAS coverage $(19.8 \%)$ in the country, contrasted with averages of $30.3 \%$ in Kenya and $73 \%$ in sub-Saharan Africa [16, 17]. Although there is a national decrease in infant mortality [18], western Kenya has the second highest under five mortality $(121 / 1,000$ live births) in the country [16].

Despite its important roles and existing knowledge about the consequences of its deficiency and access to abundant cheap foods that are pro-vitamin A rich in poor resource areas, VAD still remains a widespread problem worldwide, particularly among young children [19]. Promotions of nutrition education, home/kitchen gardens and rearing of small livestock to improve VA intake are traditional interventions for VAD control and prevention. Indeed, the Kenyan Ministry of Health through its national food and nutrition security policy has recommended that more research is needed on the knowledge, attitudes and practices towards VAD control [20]. The success of these control initiatives involving the community depend on the level of the communities' uptake of the program, which is hinged upon understanding community knowledge and practices towards VAD and recommended preventive and control measures. This study therefore assessed community awareness on existence, signs and symptoms, causes, control of VAD as well as attitudes, so as to identify knowledge gaps among health workers and caretakers/mothers, the findings of which will inform bridging of identified gaps in order to strengthen VAD control interventions at community level in Busia and Bungoma Counties of western Kenya.

\section{Materials and Methods}

\subsection{Research Setting}

The study area comprised of selected sub-counties in Bungoma and Busia Counties of Western Kenya (formerly Western province). Farming is the main economic activity in the two counties. Bungoma is a sugarcane growing area, with one of the country's largest sugar factories, as well as numerous small-holder sugar mills. Maize is grown for subsistence, alongside pearl millet and sorghum. Dairy farming is also widely practiced, as well as poultry keeping. The area experiences high rainfall throughout the year, and is home to several large rivers, which are used for small-scale irrigation [21]. Busia County borders Lake Victoria to the South West, the republic of Uganda to the West, North and South East. The County constitutes seven constituencies namely Teso North, Teso South, Nambale, Matayos, Butula, Funyula and Budalangi. The study site was Bunyala subcounty which has an area of $306.5 \mathrm{~km}^{2}$, out of which $120 \mathrm{~km}^{2}$ is under permanent water surface of Lake Victoria. The County lies between Latitude $0^{\circ} 1$ ' $36^{\prime \prime}$ South and $0^{\circ} 33^{\prime \prime}$ North and Longitude $33^{\circ} 54^{\prime} 32^{\prime \prime}$ East and $34^{\circ} 25^{\prime} 24^{\prime \prime}$ East. The main economic activity in larger Busia is trade with neighboring Uganda, with Busia town - the County Headquarters - being a cross-border centre. Away from town, the County's economy is heavily reliant on fishing and agriculture, with cassava, millet, sweet potatoes, beans, and maize being the principal food crops [22].

\subsection{Study Design}

The study used cross-sectional and qualitative methods based on framework analysis techniques. Survey tools were developed and piloted in a different health facility where the main interview was not done. The pilot facilities had similar characteristics as those where the actual study survey was carried out. Since generally 4 focus group discussions (FGDs) are considered adequate for a given research question with a given group of target study participants [23], eight FGDs (4 in Busia and 4 in Bungoma) were conducted so that each category was represented by two groups (pregnant and lactating mothers) so as to minimize bias of chance. A maternal history of night blindness during a recent pregnancy ending in a live birth was sought [24].

\subsection{Data Collection}

Socio-demographic profile questionnaire was administered to all the participants in 2014. Qualitative data were collected through FDGs and key informant interviews (KIIs). The FGDs were conducted with pregnant and lactating mothers to gauge their awareness on existence, signs and symptoms, causes, control of VAD as well as attitudes towards VAD. The KIIs were conducted on frontline health workers (at health facilities) on VAD and its control. The officer incharge assisted in mobilizing the women at the health facility and worked with a community health worker to mobilize women at the community. The KIIs were conducted before the FGDs in order to get views of frontline health workers about VA and VAD which would facilitate focused questions to understand the feelings of the pregnant and lactating mothers, thus both were used to complement each other. The data was collected by trained Kenya Medical Research Institute (KEMRI) personnel using both audio recorders and field notes. Additionally, a team of supervisors and coordinators provided further understanding of possible factors influencing VAD status during the survey. Eight FGDs, each comprising 10-12 participants, and 8 KIIs were conducted on purposively selected respondents. The participants were screened for eligibility before the discussion commenced to avoid selection bias. The criteria was that one must have lived in the study area for more than six months, be an adult and able to articulate their speech bearing in mind the representation from all the sub-units. While research instruments in this study were administered in English and Kiswahili, a translation into the local dialect was done for those who did not understand these two languages. The FGDs lasted one and half hours and the KIIs took about one hour. The KIIs were conducted with one in-charge from each Health facility.

\subsection{Ethics Statement}

This study was approved by the Scientific Steering and the National Ethics Review Committee of KEMRI (KEMRI, 
NON-SSC\#282). Permission was obtained from the County Directors of Health, and the in-charges of the various health facilities visited in Bungoma and Busia. All participants gave written informed consent. All information given by the study participants were kept confidential and anonymity was highly observed. No personal identifiers were used during data entry and analysis.

\subsection{Data Management and Analysis}

All the qualitative data collected was transcribed verbatim and the text typed into the computer. The data cleaning and analysis was done using ATLAS.ti version 6. A code sheet was created following the focus group and the key informant guides after which, the textual data was coded into selected themes and a master sheet analysis was carried out, giving all the responses from the FGDs and KIIs a theme. Thematic analysis was used where responses were categorized into themes and then ideas formulated by looking at the patterns of responses [25]. Analyzed data were presented in text form.
Quantitative data from the socio-demographic profiles was analyzed using excel spreadsheets.

\section{Results}

\subsection{Socio-demographic Characteristics of the Study Population}

In Busia, the mean age of lactating mothers participating in FGDs was 36 years while that of pregnant women was 20 years. Majority of the lactating mothers $(65 \%)$ had attained primary level education while the majority $(57 \%)$ of the pregnant mothers had attained post secondary education. Over $70 \%$ of the women were in marriage unions. Majority of the lactating mothers $(36 \%)$ were involved in skilled labor and fish mongering (27\%). Pregnant women were mainly involved in subsistence farming (14\%), unskilled labour (24\%), fish mongering (14\%) and salaried work (10\%) (Table 1).

Table 1. Socio-demographic characteristics of the study population in FGDs in Busia.

\begin{tabular}{|c|c|c|c|}
\hline Variable & & Lactating mothers & Pregnant Mothers \\
\hline Number of participants & & 22 & 21 \\
\hline Age in years, mean (range) & & $36(25-37)$ & $20(19-24)$ \\
\hline \multirow[t]{3}{*}{ Level of Education, $n(\%)$} & Primary & $14(65)$ & $2(5)$ \\
\hline & Secondary & $6(25)$ & $8(38)$ \\
\hline & Post secondary & $2(10)$ & $12(57)$ \\
\hline \multirow{3}{*}{ Marital Status, $n(\%)$} & Married & $17(75)$ & $15(71)$ \\
\hline & Widowed & $3(15)$ & $2(10)$ \\
\hline & Divorced/separated & $1(5)$ & $1(5)$ \\
\hline \multirow[t]{8}{*}{ Occupation, $n(\%)$} & Subsistence farming & $1(5)$ & $3(14)$ \\
\hline & Skilled labour & $8(36)$ & $1(5)$ \\
\hline & Unskilled labour & $1(5)$ & $5(24)$ \\
\hline & Business owner & $2(9)$ & $1(5)$ \\
\hline & Unemployed & $1(5)$ & $5(24)$ \\
\hline & Fish Monger & $6(27)$ & $3(14)$ \\
\hline & Salaried worker & $1(5)$ & $2(10)$ \\
\hline & other & $1(5)$ & $1(5)$ \\
\hline
\end{tabular}

Table 2. Socio-demographic characteristics of the study population in FGDs in Bungoma.

\begin{tabular}{|c|c|c|c|}
\hline Variable & & Lactating mothers & Pregnant Mothers \\
\hline Number of participants & & 28 & 18 \\
\hline Age in years, mean (range) & & $32(25-37)$ & $20(19-24)$ \\
\hline \multirow[t]{4}{*}{ Education, $n(\%)$} & None & $1(4)$ & 0 \\
\hline & Primary & $15(54)$ & $11(61)$ \\
\hline & Secondary & $8(29)$ & $6(33)$ \\
\hline & Post secondary & $4(14)$ & $1(6)$ \\
\hline \multirow[t]{4}{*}{ Marital Status, $n(\%)$} & Single & $4(14)$ & $3(17)$ \\
\hline & Married & $18(64)$ & $12(67)$ \\
\hline & Widowed & $3(11)$ & $1(6)$ \\
\hline & Divorced/separated & $3(11)$ & $2(11)$ \\
\hline
\end{tabular}




\begin{tabular}{llll}
\hline Variable & & Lactating mothers & Pregnant Mothers \\
\hline Occupation, $n(\%)$ & Subsistence farming & $4(14)$ & 0 \\
& Skilled labour & $3(11)$ & $3(17)$ \\
& Unskilled labour & $11(39)$ & $5(28)$ \\
& Business owner & $2(7)$ & $1(6)$ \\
& Student & $1(4)$ & 0 \\
& Unemployed & $4(14)$ & $3(17)$ \\
& Fish Monger & 0 & $1(6)$ \\
& Salaried worker & $2(7)$ & 0 \\
\hline
\end{tabular}

In Bungoma, the mean age of lactating and pregnant mothers participating in FGDs was 32 and 20 years, respectively. Majority of the lactating mothers had attained primary (54\%) level education while those who had attained secondary and above were $43 \%$. Pregnant mothers who had attained primary education were $61 \%$ while $39 \%$ had attained secondary education and above. Over $60 \%$ of the participating women were in marriage unions. The women were involved in various occupations with the majority being involved in unskilled labour for both groups of participants (lactating mothers: 39\%; pregnant mothers: 28\%); the rest were involved in skilled labor (less than 20\%), fish mongering ( $6 \%$ pregnant mother), subsistence farming (14\% lactating mothers), own business (less than 10\%), unemployed (less than 17\%), students (4\%) and salaried employment (less than 11\%). (Table 2).

The KIIs from the 2 Counties were categorized by gender. The mean age of the males was 40 years while that of females was 28 years. They had all attained at least college education. All the males were in marriage unions, whereas $20 \%$ of females were single and $80 \%$ were in marriage unions. The expertise of the participants in the 8 KIIs were as follows: 4 nurses, 1 clinical officer, 1 Assistant Clinical Officer and 2 Nutritionists (Table 3).

Table 3. Socio-demographic characteristics of key informants in Busia and Bungoma.

\begin{tabular}{|c|c|c|c|}
\hline Variable & & Male & Female \\
\hline Number of participants & & 3 & 5 \\
\hline Age in years, mean (range) & & $40(35-44)$ & $28(27-38)$ \\
\hline \multirow[t]{3}{*}{ Education, $n(\%)$} & Primary & 0 & 0 \\
\hline & Secondary & 0 & 0 \\
\hline & University & $1(33)$ & $1(20)$ \\
\hline \multirow[t]{3}{*}{ Marital Status, $n(\%)$} & Married & $3(100)$ & $4(80)$ \\
\hline & Widowed & 0 & 0 \\
\hline & Single & 0 & $1(20)$ \\
\hline \multirow[t]{4}{*}{ Expertise, $n(\%)$} & Nurse & $1(33)$ & $3(60)$ \\
\hline & Assistant Clinical Officer & 0 & $1(20)$ \\
\hline & Doctor & 0 & 0 \\
\hline & Nutritionist & $1(33)$ & $1(20)$ \\
\hline
\end{tabular}

\subsection{Awareness About Local Name (s), Existence as Well as Signs and Symptoms of Vitamin A Deficiency}

Awareness of VAD, existence of local name (s), and knowledge on signs and symptoms of VAD was expressed to some extent by the health workers (in-charge of health facilities) though with confidence from scientific understanding VA and VAD aspects. The participants generally voiced that VAD was a very rare condition and that they had not experienced it at their places of work. There were confusions in some discourse responses given by the health workers depicting ignorance or lack of adequate scientific background. Vitamin A symptoms were confused with Vitamin D. This situation reflected poor knowledge of health provider. It appears that correct discourses only depicted basic knowledge rather than scientific grounding.

"....Vitamin A deficiency is a condition in which someone is lacking vitamin A in their body. In pregnant mothers, the signs are blurred vision and night blindness. You don't see well at night. In infants, they almost have the same because if a child doesn't eat vitamin A, then their vision won't be good; they won't be able to see well. I have not seen any of late, if they are there then they must be very rare..." (Nurse in-charge, Busia County-KII).

".... It is a state of the body; lacking nutrients from vitamin A. I don't know how to call it in another language! Lacking vitamin $\mathrm{A}$ is either due to nutritional deficiencies 
or due to some disease. You see vitamin A is a small, small, small disease. Knowing its ... [signs and symptoms] is not easy! We always treat it but, diagnosing it..., No I don't know! I know that when you lack vitamin A, you will get rickets, in babies and also you will get eyesight problem. No! Vitamin A does not bring rickets, No! Vitamin D is the one causing that. [Nurse in-charge, confuses vitamin A and Vitamin D in babies but later corrects herself]..." (Nurse in - charge, Bungoma County-KII).

Some health workers seem not to be aware that VA is a nutrient and describe it as a set of nutrients. Mothers do not use names of their own to describe VAD. Majority of the frontline health workers are not sure about VAD and are not able to suspect VAD in both children and mothers. There are no routine tests for night blindness and therefore no records of its presence. Some respondents believe that VAD is just a small disease whose symptoms are not known and may be confused with other diseases.

“....VAD mostly affects children and it's where you will get a child with problems with the skin [.....] I have not seen VAD, it's a rare condition." (A Nurse in - charge Busia County)

"....VAD is the lack of Vitamin A in the body and some patients will present with some complications like eye problems and others. Some of them will present with complications $[\ldots .$.$] the pre-term babies may have other$ deformities. Infants, they will present with may be dry skin, also the eyes will be dry, which means there is no lubrication of the cornea. [....] For those who do report night blindness no, we don't have data..." (A Nurse in charge, Busia County)

"....It is lack of the required level of vitamin $\mathrm{A}$ in the body. In pregnant women mothers, we have ... anaemia is one of them, blurred vision, I mean poor sight. Infants, we also have anaemia. There is also that eye problem. Jaundice could be one of them. It also affects the growth of the baby. [....] But rare, if they are there, they are few...." (A nurse in -charge, Bungoma County)

Healthcare workers seemed to blame poor knowledge of food preparation as compromising factor to VA. There was a general feeling of wastage during the preparation value chain which could be attributed to ignorance.

"........ Like for sweet potatoes, the way they prepare [..... like vitamin A, in sweet potatoes, you know how it's got! So, you will find someone has totally peeled it off! So he/she doesn't know how to get that vitamin A in that $[\ldots . . .$. This is all about ignorance..." (A nurse in charge, Bungoma County)

\subsection{Knowledge and Awareness About Vitamin A and Vitamin A Deficiency Amongst Pre-and Post-Natal Mothers}

There seemed to be no local name that describes VAD since the respondents were not even aware of its existence. Even though some of the participants declared having heard about VA/VAD before, especially during schooling, generally the level of awareness was low. Many of those who reported to have heard about VAD thought that it is anemia, did not know its correct signs and symptoms, treatment and prevention. Some also stated that they had never heard about VAD at all. Despite lack of knowledge about VAD and its control, all of the respondents reported to have taken or allowed their child/children to be given vitamin A capsule (VAC). If there is any nutrition education given to mothers at the clinics, then the component of VA and VAD is completely lacking and both children and mothers only get the VAC during the 9 months post-natal visits after which the mothers stop bringing children to clinics.

[When asked to explain what vitamin $\mathrm{A}$ is and its importance, all participants laugh, and respond in unison,] "We don't know what the red drug is used for. All we know is that, it is for vitamin A" (Busibwabo dispensary Post natal mothers)

"... From my side, I just hear children being given vitamin A, but I don't know what it's meant for, maybe you could explain that to me...." (29 year old, mother visiting Matayos Health Center. post natal clinic)[All other Participants agree with her]

"....We are only told its vitamin A, but we are not told of its function..." (28 year old, Nambale Sub-county hospital, post natal mother) [Other participants are in agreement with her]"

“....We have never asked! We have never asked! [All participants respond in unison] We are always told it's a vaccine! .... (One of the participants, Mahonge dispensary Post natal mother)

Although the health workers stated that VAD was a very rare problem with some saying that they had not experienced it at their places of work, there were mothers who reported difficulty seeing in deem light during and after pregnancy. This could be symptoms of VAD which are exhibited among the mothers of children.

Table 4. Knowledge about VA supplements.

\begin{tabular}{|c|c|c|}
\hline What is Vitamin A supplement & No. of response & $\%$ \\
\hline "...helps to protect the body from disease...." & $6 / 48$ & 12.5 \\
\hline "....It prevents polio...." & $4 / 48$ & 8.3 \\
\hline ".... It helps the child have appetite...." & $4 / 48$ & 8.3 \\
\hline “.... gives him good health...” & $3 / 48$ & 6.3 \\
\hline "....It's for preventing the disease...so that the baby is not attacked by night blindness...." & $3 / 48$ & 6.3 \\
\hline “...It prevents malaria...." & $2 / 48$ & 4.2 \\
\hline “...It prevents pneumonia...." & $1 / 48$ & 2.1 \\
\hline $\begin{array}{l}\text { [All participants laugh, "....We don't know what it is used for. All we know is that, it is for vitamin A].......we are not } \\
\text { told what it is...." }\end{array}$ & $32 / 48$ & 66.7 \\
\hline
\end{tabular}


“....There could be sunshine for example and with this pregnancy, moving from the sun going into the house, you will see darkness. This can take between two and three minutes, it's when you start seeing properly again. [Have you experienced it at night...] I personally have experienced it. At times when coming from the house at night, I am not able to see totally and therefore have to stand like for five minutes, that's when I can start seeing some light...." (29 year old woman, on her $1^{\text {st }}$ trimester visit to Busibwabo Pre-natal clinic-Busia).

“........It takes me like one minute to see. It affects me a little. [When coming from where there is light, going into the house? Whenever you are expectant or after delivery?] Even now! [Even now? And have you seen the doctor?] No!" .... (22 year old woman visiting Khaoya post natal clinic-Bungoma).

“.... Mine takes like five minutes! [Your eyes?] Yes! And they are itchy [they only itch, but you can see properly?] No, it takes time! [For you to see properly?] Yes! [And have you informed the doctor?] I visited Webuye (a different health facility), some time back and I was told to go back, but I did not go back.........." (23 year old woman visiting Khaoya post natal clinic-Bungoma).

All these women appear to be describing some form of blindness but are not aware that this could be as a result of VAD. Regarding knowledge about VAS, participants gave very varied responses and nearly half of the participants in both groups confused VAS with polio vaccine, anti-malarias, and appetizers amongst other preventive and curative services given at clinics. Sixty seven percent of the women interviewed about knowledge on VAS said they were not aware of its importance because they were not told what it is (Table 4).

\subsection{Sources of Information About VA and VAD}

Since most mothers started attending antenatal clinics quite late into the pregnancy and those for post-natal stopped taking their children to clinics after 9 months, getting information at the health facility was not adequate. The participants suggested that they would like to learn more about VA and VAD in the following areas: signs and symptoms, prevention and control, and who are at risk of developing VAD. They suggested various means that information about VA and VAD could be passed to them. These were: door-to-door campaigns, chief barazas (community meetings), funerals, posters, church, over the radio and hospitals.

“........I suggest that door-to-door campaigns would do much good because ...........When someone come to your house......particularly if you know them, and talk to you, you will come to understand what this sickness is and what VA is." 26 year old woman attending pre-natal Tongaren Health center-Bungoma (FGD)

" .......We can use CHWs in the community so that they can mobilize, people know them, and if they are mobilized and told there is something to be shared, the people will gather and then the facilitators come and give out the information...." (Women attending pre- natal clinic at Nambale Sub-county -Busia (FGD)

\subsection{Meaning of a Balanced Diet}

Majority of the participants perceived that a balanced diet was one that consisted of all the three main classes of nutrients including carbohydrates, proteins and vitamins. This component only focused on macronutrient, a clear knowledge gap on micronutrient components of diet. Occasionally some voices mentioned vitamins indicating micronutrient components in the awareness context. However, such voices lack specificity on micronutrient issues in the realm of balanced diet.

“....A balanced diet is making sure you eat body building foods like Ugali (local food made from maize flour), beans, beef and also fats. You also feed on vitamin giving foods like fruits and those that protect you from diseases. And not forgetting water, you also make sure you drink some water, and have some energy giving foods also...." (26 year old woman, attending a pre-natal clinic at Busibwabo dispensary-Busia).

“....A balanced diet is feeding your child on different food types containing carbohydrates, vitamins, proteins, fats and oils..." (23 year old woman, attending a pre-natal clinic at Matayos health center-Busia)

"....A balanced diet is one that gives the baby energy, vitamins and proteins like for example eggs, fruits and ugali..." (25 year old woman, attending a post-natal clinic at Matayos health center-Busia)

“....Proteins, carbohydrates, and vitamins..." (22 year old woman attending a post-natal clinic at MahongeBungoma)

There seemed to be poor understanding of food belong food classification in terms of nutritional value. Amongst the responses given to describe carbohydrate giving foods, sugarcane and avocado emerged as the most frequently mentioned. Protein rich foods were surprisingly fruits, "mrenda" (local vegetable), kales, Avocado, and blue band (margarine) as one of the protein giving sources of food. This confusion in nutrient identification justifies poor knowledge and awareness of VA and VAD.

"....Changing diet, if today you take Fish and 'Ugali', tomorrow you will take rice and 'Irish' potatoes...." (23 year old woman, attending a pre-natal clinic at Tongaren Health center-Bungoma)

“...Energy giving foods are, 'Ugali', Sweetpotatoes, Sugarcane [other participants laugh at the response] Cassava, Porridge, Avocado...." Proteins include; blueband, fish, milk, eggs. Vitamins include; kales, carrots [...]" (Women attending pre natal clinic at Tongaren Health center-Bungoma)

“...Proteins include; Fruits, beef, Kales, Avocado. Vitamins include; fruits and some greens. Carbohydrates include; 'Ugali', cassava, cooked bananas, sweetpotatoes...." (Women attending pre- natal clinic at Khaoya Health center-Bungoma) 


\subsection{Importance of Having a Balanced Diet During and After a Pregnancy}

Repeated voices appeared to attest to the fact that participants had some prior knowledge on the importance of having a balanced diet, during and after a pregnancy. Amongst the reasons for having a balanced diet, during and after a pregnancy included: to regain strength and blood lost during delivery, for the mother and baby to have good health, have enough milk for the baby and to improve the baby's immunity. All these reasons somehow relate with vitamin A functions.

"...To regain blood lost during delivery! And to gain back strength. I have only that..." (20 year old woman attending post natal clinic at Busibwabo dispensary-Busia)

"....You have to feed on energy giving foods, and be healthy so as to ensure the baby gets enough milk during breast feeding...." (26 year old woman attending post natal clinic at Busibwabo dispensary-Busia)

"....An expectant woman should feed well because, since she is expectant, she has a fetus in her tummy and therefore she is supposed to be healthy so that when the day comes to deliver, she will be strong and will regain blood lost during delivery and avoid dizziness every now and then. That's the reason for a pregnant woman feeding on a balanced diet...." (29 year old woman attending post natal clinic at Matayos Health center-Busia)

"....We feed on a balanced diet, so that the woman giving birth can have strength. Mostly after delivery, we feel weak. So we feed on a balanced diet, so as to regain back our health and also have enough breast milk for the baby...." (29 year old woman attending post natal clinic at Nambale Sub-county hospital-Busia)

"....So that the mother can have completes immunity and avoid problems for the baby...." (23 year old woman attending post natal clinic at Khaoya dispensaryBungoma)

\subsection{Child Feeding Practices and Attitude Towards Nutrition and Vitamin $A$}

Testing the foods adequacy for their children 6-23months older, women had a mixed level of aptitude in responding to the qualitative descriptions of attitudes towards dietary and child feeding practices. None of the women mentioned breastmilk as an important food that they feed to their children yet breast milk is an important source of VA.

“.... I give my child porridge from maize flour, water, soft vegetables......eeeh .... I don't know how to call in English or Kiswahili but locally it is called mrenda". \{Women respond in unison\}. (21 year old woman attending post natal clinic at Khaoya dispensaryBungoma)

“....for me I also give porridge and ugali from cassava......then ugali from cassava and vegetable or fish soup because at this age he cannot chew the fish or the vegetables ". (26 year old woman attending post natal clinic at Nambale Sub-county hospital-Busia) ....most of use give porridge from cassava or maize because that is what easy to get and cook..... \{Women respond in unison $\}$. Other foods that are recommended to us such as pumpkin, sweetpotato are expensive and sometimes off season...... some of us do not know that are fed to children of this age. (29 year old woman attending post natal clinic at Matayos Health center-Busia)

Women mentioned various foods that are available seasonally but find difficult give to their children for various reasons associated with beliefs. Some of the foods Mango was mentioned the theory behind frequent bowel movement and common cold demonstrating high level of belief strength among the caregivers.

.... Most of us do not give our children mangoes because it causes frequent bowel movements and there is a change in the colour of her stool..... \{ Women laugh and respond in unison!!\}. .....one woman......it makes my child have 'homa'.....eeeh what is this called in English....aaah! I don't know.... (Women attending pre- natal clinic at Nambale Sub-county -Busia.

\section{Discussion}

This study has shown that despite the presence of VAD there were low levels of awareness about VAD, VAS, and importance of good nutrition among the communities in Western Kenya. Generally, level of awareness and knowledge about VA and VAD amongst community members was low. These findings are similar to those of a study done at Mbagathi District Hospital in Nairobi province, where caretakers did not understand the rationale for VAS [26]. The health workers whose expertise included nursing, clinical officer, Assistant Clinical officers, and nutritionists were not able to articulate issues on VA and VAD. They were aware of VAC and even administered it to the mothers and children at the health facilities and during immunization activities. Interestingly, they were not able to correctly describe VA and VAD and could therefore not suspect the deficiency in both children and mothers. Their responses showed that VAD is just a minor disease whose symptoms they do not know clearly and may be confused for other diseases. There were no routine tests at the health facilities for night blindness and therefore no records of its presence or absence.

Although all caregivers were females who had attained at least primary level education, and were thus expected to have knowledge, positive attitudes and practices related to VA, this was not the case as seen in the low level of awareness and poor knowledge about VAD, VAS, and importance of good nutrition. This contrasts findings by Kamau et al [26] who found that education of mothers was positively correlated with the use of VAS for themselves and their children. Further, participants gave very varied responses and nearly half of the participants confused VAS with polio vaccine, anti-malaria tablets, and appetizers amongst other vaccines.

The fact that mothers allowed themselves and their children to be given VAS during scheduled clinic visits and immunization days showed that most mothers valued VAS. 
However, the responses given by the mothers about awareness on the child VAS schedules, VA given to mothers and when and why it is given to mothers, indicate that mothers did not understand the rationale for VAS. They consequently followed what they were told by health workers as a routine and this may explain why after 9 months post natal, some mothers would only attend VAS services when convenient. Mothers did not know the correct signs and symptoms, cure and prevention of VAD. Some also stated that they had never heard about VAD at all despite clinic attendance. These findings are in line with those of Birungi and Onyango-Ouma, [27], whose study on acceptability and sustainability of the focused ANC package in Kenya showed sub-optimal nutrition counseling with only one third of the women attending ANC clinics for the first time receiving nutritional counseling. Although educational sessions were recommended as part of the ANC service provision, a study in rural Uganda found that ineffective organization of this service was a major impediment to increasing maternal knowledge [28]. Additionally, in a cross-sectional survey conducted in western Kenya only $14 \%$ of the women participating in the study attended a health talk at the ANC clinic and the health topics covered during these visits were found to be limited in scope [29]. Moreover, in rural Tanzania, delivery of health information, including nutrition counseling, at the ANC clinics was noted to be among the least likely components of ANC to be effectively implemented [30].

This information indicates persistent gaps in effective counseling, specifically in nutrition topics, provided through ANC clinics and this is not surprising because: 1) the HKI food frequency [31] score lower than the minimum threshold of more than 6 days per week has been observed in approximately $90 \%$ of the children in western Kenya [32]; 2) the average household dietary diversity score for women in western Kenya was less than five, a level previously demonstrated to correlate with micronutrient inadequacy [33]. Furthermore, a cross-sectional study in rural western Kenya, found that pregnant women avoided certain foods due to various attitudes and reasons such as not wanting large babies, heart burns and stomach upsets [32].

Although this study was not designed specifically to assess night blindness among mothers, $4 \%$ of mothers who participated in this study reported having difficulty seeing in deem light during and after pregnancy, the description of which could be night blindness but which was not accorded the needed attention by both mothers and the health workers. The women thought that this is a normal experience during or after pregnancy and did not suspect that it might be night blindness. The extended postpartum risk among night blind women during pregnancy is "dormant"; that is, women carry their risk without remaining night blind [34], necessitating the history to relate to a woman's most recent pregnancy. A study in Nepal, demonstrated that women who became night blind during pregnancy had a higher risk of morbidity, anemia, malnutrition, and infant mortality and could themselves die during pregnancy and at first one to two years postpartum than those who did not $[23,35,36,37]$. The study found that there were no routine tests at the health facilities for night blindness and therefore no records of its presence or absence. Finding night blind women during pregnancy, typically through a simple but specific history, can identify high-risk women who are likely to suffer consequences of vitamin A deficiency [33] There were no local names for night blindness. This is not surprising since the participants did not know signs and symptoms of VAD. In order to effectively control VAD more work needs to be done to identify common, specific terms for night blindness and to incorporate the assessment and treatment of night blindness into primary antenatal and postnatal care [33].

\section{Conclusion and Recommendation}

Although VAD was prevalent in the study area, majority of the people in the community had low awareness. This study has highlighted weaknesses and gaps in knowledge related to VAD. It appears that knowledge gaps exists both at household, community level and facility level. Some health provider seems to display low understanding of the consequences of VAD. Likewise mothers had low understanding and wariness level of the Vitamin Sources. These findings therefore demonstrate the need to fill in this knowledge gap to ensure that both primary targets and health facility providers are well equipped with scientific and application knowledge of Vitamin A as well as details of outcome associated with its deficiency. This study therefore stresses the need for health education to raise community's awareness on VAD in such settings in order to augment prevention, control and elimination efforts.

\section{Acknowledgments}

The authors would like to thank the in-charges of the health facilities, the community health workers (CHWs), the caretakers who participated, the enumerators and the drivers who made it possible to move from place to place in the catchment areas where the study was done.

\section{References}

[1] Beaton, G. H., Martorell, R., Aronson, K. A., et al., 1994. Vitamin A supplementation and child morbidity and mortality in developing countries. Food and Nutrition Bulletin; 15: 282289.

[2] Aguayo, V. and Baker, S. K., 2005. Vitamin A deficiency and child survival in sub-Saharan Africa: A reappraisal of challenges and opportunities. Food and Nutrition Bulletin; 26: 348-355.

[3] WHO, 2009. Global prevalence of vitamin A deficiency in populations at risk (1995-2005): WHO global database on vitamin A deficiency. Geneva: World Health Organization.

[4] Ministry of Health/Kenya Medical Research Institute, 1999. Anaemia and the Status of Iron, Vitamin A and Zinc in Kenya. The National Micronutrient Survey Report. 
[5] Ngare DK, Muttunga JN \& Njonge E., 2000. Vitamin A deficiency in pre-school children in Kenya. East African Medical Journal 77, 421-424.

[6] Munene RM, Adala HS, Masinde MS et al., 2003. Vitamin A deficiency among Kenyan children as detected by conjunctival impression cytology. East African Medical Journal 80, 476-479.

[7] Siekmann JH, Allen LH, Bwibo NO et al., 2003. Kenyan school children have multiple micronutrient deficiencies, but increased plasma vitamin B-12 is the only detectable micronutrient response to meat or milk supplementation. Journal of Nutrition 133, 3972S-3980S.

[8] Nabakwe EC, Lichtenbelt WV, Ngare DK et al., 2005. Vitamin a deficiency and anaemia in young children living in a malaria endemic district of western Kenya. East African Medical Journal 82, 300-306.

[9] Ettyang GA, van Marken Lichtenbelt WD, Oloo A et al, 2003. Serum retinol, iron status and body composition of lactating women in Nandi, Kenya. Annals of Nutrition \&Metabolism 47, 276-283.

[10] Baeten JM, Richardson BA, Bankson DD et al., 2004. Use of serum retinol-binding protein for prediction of vitamin A deficiency: effects of HIV-1 infection, protein malnutrition, and the acute phase response. American Journal of Clinical Nutrition 79, 218-225.

[11] Ministry of Public Health and Sanitation, 2008. The Kenya National Technical Guidelines for Micronutrient Deficiency Control, Nairobi, Kenya.

[12] Black R, Allen L, Bhutta, L. Caulfield, M. de Onis, M. Ezzati, C. Mathers and J. Rivera., 2008. Maternal and Child Undernutrition Study Group: Maternal and Child Undernutrition: global and regional exposures and health consequences. Lancet 371: 243-60.

[13] Alvarez JO et al., 1995. Urinary excretion of retinol in children with acute diarrhea American Journal of Clinical Nutrition, 61: 1273-1276.

[14] Mitra AK, Alvarez JO, Guay-Woodford L, Fuchs GJ, Wahed MA, Stephensen CB., 1998. Urinary retinol excretion and kidney function in children with Shigellosis. Am J Clin Nutr; 68: 1095-103.

[15] Sommer A and West KP Jr., 1996. Vitamin A deficiency: health, survival, and vision. New York: Oxford University Press.

[16] Kenya National Bureau of Statistics (KNBS), ICF Macro, 2010. Kenya Demographic and Health Survey 2008-09. Calverton, Maryland: KNBS and ICF Macro.

[17] The State of the world Children, 2015. New York, UNICEF: 2014.

[18] Kenya Demographic and Health Survey, 2015. Key Indicators: Kenya National Bureau of Statistics Nairobi, Kenya.

[19] West KP., 2002. Extent of vitamin A deficiency among preschool children and women of reproductive age. J Nutrition, 132 (suppl): 2857S-66S.

[20] GoK, 2012. National Food and Nutrition security Policy. Agriculture Sector Coordination Unit (ASCU).
[21] GoK, 2009. Bungoma District Development Plan (20082012). Kenya Vision 2030. Towards a Globally Competitive and Prosperous Kenya. June 2009.

[22] GoK, 2009. Busia District Development Plan (2008-2012). Kenya Vision 2030. Towards a Globally Competitive and Prosperous Kenya. June 2009.

[23] Krueger RA., 1998. Focus groups: a practical guide for applied research. Newbury Park, CA: Sage Publications.

[24] Christian, P., West, K. P., Jr., Khatry, S. K., Katz, J., LeClerq, S. C., Pradhan, E. K. \& Shrestha, S. R., 1998. Vitamin A or $\beta$ carotene reduces but does not eliminate maternal night blindness in Nepal. J. Nutr. 128: 1458-1463.

[25] Braun V and Clarke V., 2006. "Using thematic analysis in psychology". Qualitative Research in Psychology 3 (2): 83.

[26] M. W. Kamau, A. O. Makokha, J. K. Mutai and I. K. Mugoya, 2012. Factors Influencing Vitamin A Supplementation among Mothers of Children Under Five Years Old at Mbagathi District Hospital, Kenya. East African Medical Journal Vol. 89 No. 4.

[27] Birungi $\mathrm{H}$ and Onyango-Ouma W., 2006. Acceptability and sustainability of the WHO focused antenatal care package in Kenya. FRONTIERS Final Report. Washington, DC: Population Council; pp. 32-13.

[28] Conrad P, De Allegri M, Moses A, Larsson EC, Neuhann F, Müller O, Sarker M., 2012. Antenatal care services in rural Uganda: Missed opportunities for good-quality care. Qual Health Res.; 22 (5): 619-629. doi: $10.1177 / 1049732311431897$.

[29] Van Eijk AM, Bles HM, Odhiambo F, Ayisi JG, Blokland IE, Rosen DH, Adazu K, Slutsker L, Lindblade KA., 2006. Use of antenatal services and delivery care among women in rural western Kenya: a community based survey. Reprod Heal; 3 (2) Pub Med.

[30] Magoma M, Requejo J, Merialdi M, Campbell OMR, Cousens S, Filippi V., 2011. How much time is available for antenatal care consultations? Assessment of the quality of care in rural Tanzania. BMC Pregnancy Childbirth.; 11 (64) PubMed

[31] Helen Keller International, 1993. How to use the HKI food frequency method to assess community risk of vitamin A deficiency. New York, HKI: 79p.

[32] Ouedraogo H, Sindi K, Oyunga M, Kariuki S, Vulule J, Cole D, Levin C, Thiele G, Low J., 2012. Mama SASHA baseline survey report. International Potato Centre.

[33] Kennedy GL, Pedro MR, Seghieri C, Nantel G, Brouwer I., 2007. Dietary diversity score is a useful indicator of micronutrient intake in non-breast-feeding Filipino children. $\mathrm{J}$ Nutr. 137 (2): 472-477.

[34] Rolf Klemm, Dr. PH, Philip Harvey, Ph. D., Amanda Palmer MHS., Keith P. West, Jr., Dr. PH. 2007. GAP ANALYSIS, Defining the Issues for Vitamin A Bloomberg School of Public Health, Johns Hopkins University

[35] Christian, P., West, K. P., Khatry, S. K., Kimbrough-Pradhan, E., LeClerq, S. C., Katz, J., Shrestha, S. R., Dali, S. M. \& Sommer, A., 2000. Night blindness during pregnancy and subsequent mortality among women in Nepal: effects of Vitamin A and _-carotene supplementation. Am. J. Epidemiol. 152: 542-547. 
[36] Christian, P., West, K. P., Jr., Yamini, S., Stallings, R., Sharma, S., Hackman, A., Shrestha, S. R. \& Khatry, S. K., 2001. Potentiating effect of zinc supplementation on vitamin A in curing night blindness during pregnancy in Nepal. Am. J. Clin. Nutr. 73: 1045-1051.
[37] Christian P., 2002. Recommendations for indicators: night blindness during pregnancy - a simple tool to assess vitamin A deficiency in a population. J Nutr; 132: 2884S-2888S. 